\title{
Citation:
}

Tarí, J.J., Pereira-Moliner, J., Molina-Azorín, J.F. and López-Gamero, M.D. (2019), "Heterogeneous adoption of quality standards in the hotel industry: drivers and effects", International Journal of Contemporary Hospitality Management, Vol. 31 No. 3, pp. 1122-1140. https://doi.org/10.1108/IJCHM-09-2017-0606

\section{Heterogeneous adoption of quality standards in the hotel industry: drivers and effects}

Purpose - This paper examines the impact of external and internal drivers on the dimensions of internalization (daily practices and continuous improvement) of quality standards, the relationship between the dimensions of internalization and their effects on customer, employee, society and organizational results in hotels.

Design/methodology/approach - The study applies a structural equations analysis to test these relationships using empirical data from 176 quality-certified hotels.

Findings - Hotels need internal drivers to internalize a quality system because the external drivers themselves are not able to explain significantly the quality internalization process. This paper shows the significant relationship between the dimensions of internalization (daily practices and continuous improvement), and the importance of continuous improvement (e.g., innovations from quality standards and reflection on how to improve the current work processes) for improved customer, employees, society and organizational results.

Originality/value - To the best of our knowledge, there are no empirical studies jointly analysing the drivers of internalization, the relationship between the dimensions of internalization and their effects on different dimensions of results (customers, employees and society) in hotels.

Keywords Quality standards, Internalization, Drivers, Performance, SEM.

Paper type Research paper 


\section{Heterogeneous adoption of quality standards in the hotel industry: drivers and effects}

\section{Introduction}

Many hospitality firms implement quality standards and service quality models to improve their results in response to external and/or internal motivations (e.g., ÁlvarezGarcía et al., 2016; Amin et al., 2017; Lai and Hitchcock, 2016; Pereira-Moliner et al., 2016; Sanchez-Ollero et al., 2015). The literature reports mixed results regarding the effects of quality standards on results. Some scholars have found that quality standards lead to improved performance (Allur et al., 2014; Chow-Chua et al., 2003), while others have shown that it does not actually produce any improvement in performance (Lo et al., 2011).

In this context, most previous work on quality standards has assumed a homogeneous adoption of the standard, measuring it as a binary variable (certified firm/non-certified firm) (e.g., Bayo-Moriones et al., 2011; Kusumah and Fabianto, 2018; Mak, 2011). A few studies have considered a heterogeneous adoption of quality standards, which is to say that they have considered that organizations may adopt quality standards in different ways (Atasaven et al., 2014; Briscoe et al., 2005; Naveh and Marcus 2005). For instance, some organizations adopt the requirements of the quality standard in a token way, whereas others believe in the quality philosophy and develop a full adoption (Boiral and Roy, 2007; Prajogo et al., 2012). The latter approach involves the incorporation of the quality standards onto the philosophy and workings of the organization, so that the heterogeneous adoption of quality standards refers to the extent to which organizations internalize the standards. The studies that have considered internalization have measured the adoption of the quality standard with several items. 
According to the practice-based view, this heterogeneous adoption (or internalization) that organizations can develop for quality standards may help to explain the different benefits across organizations from that adoption in practice. This view suggests that practices in the public domain (e.g., setting goals, regular maintenance of machines, and quality standards) can be implemented in different ways and such variation explains the different performance levels achieved by organizations. Thus, impact on performance varies depending on the use of specific practices, how organizations use them, and the interaction of these practices with other practices in the organization (Bromiley and Rau, 2014).

Based on this view, and as it is not clear how the quality standard internalization process improves performance, new studies on the internalization process are needed (Cai and Jun, 2018). It seems clear that internalization reinforces the potential benefits of the quality standard, but there is a lack of studies analysing the effects of the internalization of quality standards on other dimensions of performance (e.g. customers, employees and society), the role of certain drivers of internalization (e.g., quality culture, management commitment, system coordination with suppliers, and innovation) and the possible relationship between internal and external drivers in the case of hospitality firms. As prior research has mainly examined the internalization of quality standards in manufacturing sectors, the present paper examines the relationships between internal and external drivers, internalization dimensions and different performance dimensions in the case of hotels to fill in this gap. This study analyses hotel firms located in Spain because this country is the second most important tourist destination worldwide for international tourism receipts and the third most important destination in international tourist arrivals (UNWTO, 2017, p. 6). 
Therefore, the aim of this study is to analyse the impact of external and internal drivers on the dimensions of internalization (daily practices and continuous improvement), the relationship between the dimensions of internalization, and its effects on customer, employee, society and organizational results in hotels.

\section{Theory and hypothesis development}

\subsection{Internalization}

The concept of "internalization" describes the process whereby an organization integrates the requirements of a quality standard in its daily practices in order to secure continuous improvement. Based on the practice-based view, firms can integrate the requirements of the quality standard in their daily routines in a heterogeneous way and these differences in the implementation may lead to different performance levels. For example, a symbolic integration means that firms adopt the standard in a superficial way. A full adoption of the standard means that firms implement the requirements of the standard in a more profound way. These ideas suggest that the standard might be adopted in a basic or an advanced form (Naveh and Marcus, 2005; Prajogo et al., 2012). Studies of internalization have used one or a number of constructs to measure the degree of integration. For instance, Naveh and Marcus (2005) used four constructs (two of which could be considered internalization drivers); Briscoe et al. (2005), two constructs; and Allur et al. (2014), Atasaven et al. (2014), Christmann and Taylor (2006), Nair and Prajogo (2009), Prajogo (2011), and Tarí et al. (2013) consider a construct with several items.

Based on these works, two levels of internalization may be identified: daily practices and continuous improvement. Daily practices represent a basic level of internalization whereby companies start the implementation of a quality standard, by 
using the documents created in their daily routines and offer training to employees to follow the documents and standards (e.g., quality policy, objectives, and procedures). Continuous improvement is a more advanced level, because the organization uses the requirements of quality standards and invests time and resources to introduce new practices, improvements and innovations in its activities.

Although some previous studies on internalization mentioned the existence of a basic level and a more advanced level (Briscoe et al., 2005; Naveh and Marcus, 2005; Prajogo et al., 2012), they did not look into the relationship between these two levels.

In order to internalize the quality standard, organizations provide training for their employees and carry out audits, all of which can lead to improved processes (Ataseven et al., 2014; Cai and Jun, 2018). Training (for instance, in problem solving) and measuring processes make it easier to introduce improvements in processes (Kim et al., 2012). This supports the idea that training, audits and other follow-up actions which are usually implemented by organizations adopting a quality standard may be integrated into work routines in order to facilitate continuous improvement, that is, making daily practices lead to continuous improvement.

\section{H1: Daily practices have positive effects on continuous improvement.}

\subsection{Internal and external drivers of internalization}

The external drivers are the demands of stakeholders (e.g., customers' demands, public image and environmental protection) that influence the adoption of the quality standard in a heterogeneous way, for example, to gain a quality certificate. The internal drivers are the intrinsic motivations that a company imposes on itself to adopt the standard quality (e.g., resources and capabilities such as management commitment, quality culture 
for continuous improvement, innovativeness, written documentation, and improved coordination with suppliers/intermediaries) that affect the adoption of the quality standard. According to previous studies on internalization, internal (Prajogo, 2011) and external (Christmann and Taylor, 2006) drivers related to reasons for certification may influence the basic or advanced adoption of a quality standard. In addition, internal drivers are more important than external drivers for a fuller development of quality standards. In this context, other authors state that external drivers for certification have no impact on the in-depth implementation of the ISO 9001 standard (Jang and Lin, 2008).

The literature on internalization has focused on internal drivers related to reasons for certification, and few studies have considered other internal drivers: quality culture, leadership, coordination with suppliers and an environment of service innovation. These few studies point out that a quality-proactive culture reduces the reluctance to adopt the requirements of a quality standard and to the organization creating a culture enabling a higher level of internalization (Briscoe et al., 2005). Concerning leadership, the management's policies, plans and actions may help the organization to focus more on the customer, train its employees and improve relations with suppliers (Singh, 2008), which lead to a more advanced development of quality standards (Heras-Saizarbitoria and Boiral, 2015). Similarly, firms facing more dynamic environments are more likely to invest in creating a quality culture (Briscoe et al., 2005) and such a quality culture, as has been said, facilitates internalization. Systematic coordination with tourist suppliers also increases the level of internalization (Briscoe et al., 2005; Naveh and Marcus, 2005).

This review indicates that internal drivers may influence the level of internalization (daily practices and continuous improvement) and that, even though the effects of external drivers are not clear, it may be considered that they have an impact on internalization, although to a lesser extent than internal drivers. Moreover, as Jang and 
Lin (2008) found in relation to internal and external reasons for ISO 9001 certification, there could be a relationship between external and the internal reasons. Singh et al. (2011) pointed out that, although organizations seek certification for external reasons, some of them do obtain benefits because they modify their internal processes in order to obtain certification. Therefore, these hypotheses are proposed:

H2.1: External drivers have positive effects on daily practices.

H2.2: External drivers have positive effects on continuous improvement.

H3.1: Internal drivers have positive effects on daily practices.

H3.2: Internal drivers have positive effects on continuous improvement.

H4: External drivers have positive effects on internal drivers.

\subsection{Effects of internalization on results}

Although the effects of internalization on operational and financial performance have been widely examined in studies on internalization (Allur et al., 2014; Briscoe et al., 2005; Jang and Lin, 2008; Naveh and Marcus, 2005), there is a lack of studies analysing the effects on other results such as results for customers, employees and society. The studies on the European Foundation for Quality Management (EFQM) model propose that there are results related to customers (e.g., customer satisfaction, quality of service, and loyalty), employees (e.g., employee satisfaction, motivation, productivity, and absenteeism) and society (e.g., environmental protection, ethical behaviour, prevention of risks) derived from quality practices (Gómez Gómez et al., 2015), which have not been analysed in relation to internalization of a quality standard.

In this context, internalization causes employees to receive more training (Cai and Jun, 2018) and to be more acquainted with the quality policy, objectives and documents, 
which may enable them to become more committed to their tasks (Huarng et al., 1999). Similarly, they can use information from customers to a greater extent in order to improve quality (Nair and Prajogo, 2009). All this can lead the firm to have better trained and better motivated employees and become more tailored to tourist customers' needs and expectations. This shows that a basic or advanced level of internalization (daily practices or continuous improvement) may have an impact on customer and employee results (Allur et al., 2014; Ataseven et al., 2014; Christmann and Taylor, 2006; Prajogo et al., 2012). Quality initiatives may also affect customer and employee results in the case of tourism organizations (Amin et al., 2017; Molina-Azorín et al., 2015; Nunkoo et al., 2017; Sanchez-Ollero et al., 2015). According to this review, daily practices and continuous improvement can improve customer results (e.g., customer satisfaction, fewer complaints, loyalty) and employee results (e.g., employee satisfaction, motivation, employee productivity).

H5.1: Daily practices have positive effects on customer results.

H5.2: Continuous improvement has positive effects on customer results.

H6.1: Daily practices have positive effects on employee results.

H6.2: Continuous improvement has positive effects on employee results.

Studies on internalization have not analysed its effects on the organization's social impact. Nevertheless, it is known that quality management practices can have positive effects on the development of environmental practices, because firms concerned with quality may reduce waste and try to be more efficient (Alves et al., 2017). For instance, an organization may include environmental criteria in its design and its processes in order to minimize environmental impact (Handfield et al., 2001; Klassen and McLaughlin, 
1993). Also, some scholars have found positive effects of quality standards for other stakeholders beyond employees and customers, such as, for instance, authorities (Posinska et al., 2002).

These ideas indicate that when quality practices are more developed it is easier to develop other similar practices. Thus, considering that various studies have found that quality practices facilitate the development of environmental practices (Curkovic, 2003; Pereira-Moliner et al., 2012) and socially responsible practices (Withanachchi et al., 2007), and that hospitality organizations that adopt quality initiatives can achieve positive environmental impacts (Molina-Azorín et al., 2015), it may be suggested that daily practices and a higher level of internalization (continuous improvement) might lead to a greater commitment to the environment and other social aspects. Therefore, it may be hypothesized that:

\section{H7.1: Daily practices have positive effects on society impact.}

\section{H7.2: Continuous improvement has positive effects on society impact.}

Finally, various studies on the EFQM model mention that customer, employee and society results lead to improved organizational performance (e.g., market share, sales, profitability and costs) (Gómez Gómez et al., 2015; Heras-Saizarbitoira et al., 2012). This type of relationship has not been analysed in internalization studies. In the case of tourism organizations, the literature shows that customer and employee satisfaction affects repurchase intentions and organizational performance (Amin et al., 2017; Su et al., 2016) and therefore market share and sales can be increased. These customer, employee and society results may affect organizational performance in hospitality contexts, for example, because satisfied employees will contribute to delivery of high-quality services 
(Amin et al., 2017), satisfied customers can revisit a hotel or restaurant (Su et al., 2016) and positive environmental impacts may reduce costs (Molina-Azorín et al., 2015). That is, sales can be increased and costs can be reduced. These ideas suggest that:

H8: Customer results have positive effects on organizational performance.

H9: Employee results have positive effects on organizational performance.

H10: Society impact has positive effects on organizational performance.

Figure 1 shows the theoretical model proposed in this research work.

\section{Study method}

\subsection{Sample}

The analyses in this study are applied to hotel firms located in Spain. In Spain, the tourist industry is a strategic activity for the economy. For this reason, the Government promotes competitiveness in this industry by developing quality management systems through the Institute for Spanish Tourism Quality (ICTE), through which the ICTE's Q quality certificate may be obtained. The Q certificate is compatible with the ISO 9001 certificate, and includes specific requirements for the hotel industry (such as size of beds, furniture and the number of towels in rooms according to the category of the hotel). A Spanish proposal to develop the new international ISO standard for the hotel industry has been promoted by the ICTE and it has finally been approved with the support of 35 countries. For example, the Presidency and the Secretarial of the Committee that will prepare this ISO standard for the hotel industry will be Spanish (ICTE, 2018).

The population consists of 415 hotels which have received the Q certificate in Spain. The ICTE's database of September 2014 was used to identify the population. The 
questionnaire was distributed by post and by email in three waves between October and December 2014 , the data collection process closing on January $31^{\text {st }}, 2015$. In the end a total of 176 filled-in questionnaires were received, for a response rate of $42.41 \%$. The letter introducing the study requested that the questionnaire be answered by the quality manager. Before the questionnaire was handed out, a pre-test was carried out with three tourist organization managers, three representatives from hotel sector, and a quality management consultant.

In order to verify that the sample is representative, the non-response bias is checked by dividing the sample into three equal-sized groups depending on the number of days elapsed since the moment the questionnaire was sent until it was received (Armstrong and Overton, 1977). After applying a Student's t analysis between the first and the third group, it is found that there are no significant differences in the average values of any of the variables measured between these two groups.

\subsection{Measures}

Drivers of internalization. Managers had to assess to what extent drivers influence on internalization, on a 1-7 scale ( 1 if the driver has no influence, 7 if it has a key influence). In order to measure internal and external drivers, a set of items was identified (Table I) on the basis of the literature review (Briscoe et al., 2005; Christmann and Taylor, 2006; Naveh and Marcus, 2005; Singh, 2008).

Internalization. The construct "daily practices" is composed of 4 items, on the basis of the work by Briscoe et al. (2005), Christmann and Taylor (2006) and Naveh and Marcus (2005) and the construct "continuous improvement", composed of 5 items, on the basis of the work by from Briscoe et al. (2005), Nair and Prajogo (2009) and Naveh and 
Marcus (2005). Managers had to assess, on a Likert-type scale, from 1 (this practice is never applied in our organization) to 7 (the practice is always applied) (Table I).

Customer results. A five-item variable was used in order to measure the results of internalization on five customer results. The items are measured with a Likert scale (1-no impact to 7-very high impact) (Table I). In order to identify the items, studies were used which had measured the results of excellence models, such as customer, employee and society results (Bou-Llusar et al., 2009; Curkovic et al., 2000) and specific work on the tourist sector (Deng et al., 2013).

Employee results. This is a six-item scale (Table I) of employee results based on quality studies (Bou-Llusar et al., 2009; Curkovic et al., 2000) and specific studies on tourism (Yeh, 2013). The quality manager had to assess the impact of internalization on these results, from 1 (no impact) to 7 (very high impact).

Social impact. A three-item variable was used (Table I) based on quality management and tourism-specific studies (Bou-Llusar et al., 2009; Kim et al., 2014; Tarí et al., 2007). Managers had to assess on a 7-point scale if the impact had been non-existent or very high.

Organizational result. This is a construct consisting of 4 items, based on the studies by Bou-Llusar et al. (2009) and Tarí et al. (2007). These 4 items measured the impact of the requirements of the quality standard, on a scale from 1 (no impact) to 7 (very high impact) (Table I).

\section{INSERT TABLE I}

\subsection{Analysis}


The hypotheses are checked by applying structural equation models, using the Partial Least Squares (PLS) approach, with SmartPLS 3 software (Ringle et al., 2014). The sample used in this study is suitable for the PLS approach. The most complex regression in our model involves seven antecedent constructs leading to an endogenous construct. Therefore, employing $G^{*}$ Power software for a one-tail $t$ test for linear multiple regressions and seven predictors (power $=0.95 ; \alpha=0.05$; effect size $\mathrm{f}^{2}=0.15$ ), the minimum sample suggested is 74 and our sample is composed of 176 firms. The power for a sample of 176 observations is $99.97 \%$ (Green, 1991, p. 503; Mayr et al., 2007).

\subsection{Evaluation of the measurement model}

The measurement model contains reflective constructs. Individual reliability of the reflective constructs demands that items have to achieve loads over 0.707 on its construct (Carmines and Zeller, 1979). Table I shows that the items fulfil this condition, with the exception of items 1 and 5 of the internal drivers. However, although these items are below the minimum level of 0.707 , Hair et al. (2017) state that those variables whose loads are between 0.4 and 0.7 (as is the case here) may be retained provided their elimination does not lead to an increase of the average variance extracted (AVE) or of composite reliability over the critical levels, 0.5 and 0.7 , respectively. Similarly, Chin (1998) believes that the 0.7 rule may be too strict, and the factor load of these items is very close to 0.7 . For these reasons it was decided to retain all the items in the "internal drivers" construct.

Construct reliability is checked by composite reliability $\left(\rho_{c}\right) . \rho_{c}$ must have values over 0.7 (Werts et al., 1974) and Table I shows that this requirement is fulfilled in all cases, 0.844 being the minimum value for composite reliability. As for convergent validity, it is measured by AVE, which must be higher than 0.5 (Fornell and Larcker, 
1981). Table I shows that this condition is satisfied in all cases, the lowest AVE value being 0.544 .

Discriminant validity concerns the extent to which a construct is different from other constructs. Two analyses are performed to test for discriminant validity. The first consists in calculating the AVE square root for each construct. These values of AVE should be higher than the correlation coefficients between the constructs (see Table II). The second method is the Heterotrait-Monotrait (HTMT) criterion (Henseler et al., 2015). The desirable values for HTMT usually included are lower than 0.85 . In our case, all the values are below 0.85 (Table II).

\section{INSERT TABLE II}

\subsection{Evaluation of the structural models}

Figure 1 and Table III show $\mathrm{R}^{2}$ and $\beta$ between the different constructs. The $\mathrm{t}$ statistics values to check the significance of the path coefficients are achieved applying a bootstrap test with 5000 subsamples. The confidence intervals at $95 \%$ are also included, in order to check that the values of $\beta$ are significantly different from 0 . Concerning the values of $\mathrm{R}^{2}$, Chin (1998) indicates that the explanation levels for the construct analysed may be classified in the following way: 0.67 substantial, 0.33 moderate and 0.19 weak.

As for the goodness-of-fitness for the structural model, it is measured by SRMR and it must be $\leq 0.08$ (Henseler et al., 2014). In the present study is equal to 0.06. In addition, the $\mathrm{f}^{2}$ indicator is analysed. This indicator determines if the influence of a specific latent variable on a dependent construct has a substantial impact, that is, it entails analysing what would happen to $\mathrm{R}^{2}$ if a new construct is added to the structural model 
(Hair et al., 2017). The potential values for $\mathrm{f}^{2}$ are classified into the following levels: 0.02 weak influence, 0.15 moderate influence and 0.35 substantial influence.

\section{Results}

This section includes the hypothesis testing and an analysis about the importance of each item included in the daily practices and continuous improvement constructs. First, the results of the structural model are those appearing in Figure 1 and Table III, which show that nine of the 15 hypotheses are significantly supported $(\mathrm{H} 1, \mathrm{H} 3.1, \mathrm{H} 3.2, \mathrm{H} 4$, H5.2, H6.2, H7.2, H8, and H9). Figure 1 and Table III show that H1 is supported, that is, the first level of internalization (daily practices) leads to the second level (continuous improvement). The results also show that external drivers do not account for any internalization level (daily practices and continuous improvement) in a significant way (neither H2.1 nor H2.2 are supported), whereas internal drivers do have an impact on the dimensions of internalization (H3.1 and H3.2). However, external drivers have an influence on internal drivers when it comes to internalizing the quality standard. This fact suggests a possible mediation effect that is discussed in the conclusion subsection. Besides, it must be pointed out that, by observing the $\mathrm{f}^{2}$ statistic, a significant and substantial relationship emerges between external and internal drivers and the two internalization levels.

\section{INSERT FIGURE 1 AND TABLE III}

Regarding the relationship between the dimensions of internalization and results, Figure 1 and Table III show that continuous improvement significantly explains all the results variables (H5.2, customers; H6.2, employees; H7.2, social impacts). However, 
daily practices do not significantly explain any of the results constructs. This fact suggests a possible mediation effect of continuous improvement between daily practices and the results that is discussed in conclusion subsection. In addition, customer (H8) and employee results (H9) have a positive influence on organizational performance, the most important impact being that of customer results. It may be observed from Figure 1 that the construct that has most influence in this model, that is with a greater $\mathrm{R}^{2}$, is organizational performance, followed by continuous improvement.

Finally, since the constructs related to daily practices and continuous improvement are the focus of this research, it is important to know which items of each construct are the most significant in the explanation of performance. To see this, the loadings of Table I are analyzed, where the greater the loading of the item, the better it is able to explain the construct. Therefore, in daily practices, the two most important issues are the integration of the quality system in daily routines and the updating of quality documents (e.g., quality policy, procedures). Regarding continuous improvement, the two most important issues are the investment of time and resources in quality issues as a way of introducing innovations and the investment of time and resources in thinking about the way work is done to identify improvements.

\section{Discussion and conclusions}

\subsection{Conclusions}

This paper clarifies what drivers are needed to increase the internalization of a quality standard and what quality issues are most important to improve customer, employee and society results in hotels. The results of this study indicate that internal and 
external drivers have an impact on the internalization of quality standards, and that organizational efforts to integrate the requirements of the standard in daily practices lead to continuous improvement which in turn is positively related to customer, employee and society results. More specifically, the study shows that nine of the 15 hypotheses are supported (see Figure 1).

Hypotheses H2.1 and H2.2 are not supported. We have conducted additional analyses to examine this issue. Specifically, the analyses show that external drivers seem not to explain significantly the two internalization constructs when we consider internal drivers simultaneously in the structural model. However, when we remove internal drivers from the structural model, that is, when the model considers only external drivers to explain the two internalization constructs, there is a significant direct relationship between external drivers and daily practices $(\beta=0.298 ; p=0.000)$ but not in the case of continuous improvement $(\beta=0.103 ; p=0.090)$. Therefore, it is important to state that the relationship between external drivers and the first level of internalization (daily practices) is fully mediated by internal drivers. So external drivers do have an influence on internal drivers when it comes to internalizing the quality standard. Those firms which are exclusively guided by external drivers may not succeed in internalizing the requirements of the quality standard. That is, external drivers alone may not be enough to produce continuous improvement. In contrast, internal drivers alone are enough to produce quality and then integrate quality standards requirements into daily routines and advance through continuous improvement. Accordingly, if hotel firms are able to create an increased interest in internal drivers from their external drivers, they may improve their internalization level and, in turn, their results. This supports the idea that internal drivers increase the possibility of hotel firms showing a greater commitment to quality and, as a result, internalizing to a greater extent the requirements of a quality standard than those 
who are led by external drivers. These internal drivers are related to facilitators of internalization (culture, leadership, etc.), and this evidence supplements studies on internalization that emphasize the importance of internal drivers related to the reasons for certification for ISO 9001 certification (Prajogo, 2011) and the role of these factors for the internalization process (Heras-Saizarbitoria and Boiral, 2015).

The results also indicate that, when a hotel firm integrates the requirements of a quality standard into its daily routines, it can advance significantly towards continuous improvement. Thus, the hotel firms analysed usually start with an internalization level where the quality documents are applied to daily routines, employees are trained, controls and audits are performed. That is, there is a progressive implementation of the requirements of the quality standard which can become a part of daily routines. On this basis, progress is made towards a continuous improvement process which makes it possible to introduce new practices in order to improve, invest time and resources in implementing more advanced practices, and improve and innovate in work processes. This supports the previous results that identified a basic and an advanced level of internalization (Naveh and Marcus, 2005; Prajogo et al., 2012) and expands on those contributions by showing that daily practices lead to continuous improvement.

The study also shows that the greater the degree of internalization and the progress in continuous improvement, the better the results for customers, employees and society, which in turn may improve the organization's results. The data indicate that daily practices do not have a significant and direct impact on customer, employee and society results. These findings may be due to the fact that there may be a fully mediating effect of continuous improvement in the relationship between daily practices and the rest of the outcome variables. When we remove continuous improvement from the structural model, that is, when the model considers only daily practices to explain the three results 
variables, there are significant direct relationships between daily practices and customer results $(\beta=0.370 ; p=0.000)$, employee results $(\beta=0.459 ; p=0.000)$, and social impacts $(\beta=0.447 ; p=0.000)$. Therefore, it is important to emphasize that daily practices alone may not be enough to improve results and, therefore, continuous improvement mediates the relationship between daily practices and customer, people and society results.

These ideas point to the fact that continuous improvement influences customer, employee and society results in a stronger way than daily practices. This indicates that, when a culture of continuous improvement is developed in a hotel, it has positive effects on customer satisfaction, service quality, web 2.0 scoring and social improvement. Other improvements, although to a lesser extent, may be attained on other results, such as employee satisfaction, motivation and productivity. In turn, all these results lead to improved organizational results. Researchers who have analysed internalization have arrived at similar conclusions regarding quality practices and operational results. For example, Ataseven et al. (2014) pointed out that improved processes lead to improved operational results. Similarly, other authors who analysed internalization found similar results concerning operational and financial results. For instance, Allur et al. (2014), Nair and Prajogo (2009) and Naveh and Marcus (2005) point out that internalization has a positive influence on operational and financial results.

Finally, the loadings in Table I suggest that integrating the quality system into daily routines, updating the quality policy and the quality system procedures to daily activities, investing time and resources as a way of innovating in a hotel and investing time and resources to analyse how activities are carried out to identify improvements are the most critical practices to improve the hotel's results.

\subsection{Theoretical Implications}


The present research work supports previous studies on internalization that partially address similar objectives (e.g., Nair and Prajogo, 2009; Naveh and Marcus, 2005) and suggests new relationships between drivers, between dimensions of internalization, and between dimensions of internalization and performance in the hotel industry. The study reinforces our knowledge on which drivers are more important for the dimensions of internalization, the relationship between the dimensions of internalization and between these dimensions and customer, employee and society results, emphasizing the importance of continuous improvement for performance.

Although prior research shows that internal and external motives for seeking ISO 90001 certification influence internalization, and that internal motivation is more important for a more complete development of quality standards (Prajogo, 2011), there has been no examination of the relationship between these drivers and the dimensions of internalization. This paper expands this prior research because it shows the impact of internal and external drivers on dimensions of internalization (daily practices and continuous improvement), and the relationship between internal and external drivers in the case of hotels. The present paper identifies the relationship between the different dimensions of internalization. The relationship between basic and advanced implementation has not been analysed before (Prajogo et al., 2012).

These previous works have also focused on the effects of internalization on operational and financial results (Jang and Lin 2008; Nair and Prajogo, 2009; Naveh and Marcus, 2005). This paper emphasizes that the dimensions of internalization may have a differential impact on customer, employee and society results and the importance of continuous improvement for increasing customer, employee and social results. Continuous improvement has been widely examined in the literature on production but less so in service industries, and minimally in the hospitality industry. 
This paper contributes to this field by relating these issues which have not previously been analysed together in the context of hotel organizations. As previous works have suggested, there is a need for more studies in different sectors, different countries (Heras-Saizarbitoria and Boiral, 2013; Nair and Prajogo, 2009) and different quality standards (Singh et al., 2011).

\subsection{Practical Implications}

The results suggest the following managerial implications. Managers must understand that it is more important to focus on internal drivers in order to internalize the requirements of a quality standard. In this respect, based on the loadings of the items (see Table I), hotel managers must consider that innovativeness, the existence of written work methods and a culture of continuous improvement are critical factors in the adoption of a quality standard in a more advanced way. This suggests that standardization and innovation are both important aspects for hotels and that they should be balanced. In addition, when managers integrate quality issues into daily routines, they should convince employees to use quality documents in their daily activities, and promote a greater commitment to the capacity to innovate so as to achieve a greater degree of internalization. These are the most important practices to reinforce customer, employee and social results. As continuous improvement is even more important for that end, hotel managers should invest time and resources in introducing innovations based on quality issues and think about current activities to improve them to use the quality standard as a mean to promote the process of continuous improvement, as a way to improve organizational results. The efforts of managers to commit themselves to actions that support the development of creative and innovative activities by employees, mainly by making the requirements a part of work routines and, on that basis, increasing the 
opportunities to innovate, allow them to improve internalization and consequently improve the hotel's results. These practices will reinforce mainly customer satisfaction and loyalty (customer results), employee satisfaction and productivity (employee results), prevention of risk and ethical behaviour (social results) and sales and profitability (organizational results).

Finally, regarding public policies, public institutions that promote quality initiatives in hospitality should inform hotel managers and employees about these issues to facilitate the internalization of quality standards. For example, through conferences, talks, training activities, and funding support to implement and certify quality standards, public institutions should reinforce the need to integrate quality requirements in daily activities and introduce innovations (e.g., minor and radical improvements in their products, services and processes) to achieve the real benefits from quality standards.

\subsection{Limitations and future research}

This study has several limitations. It uses cross-sectional data based on information from hotels. It would be interesting in the future to carry out a longitudinal study in order to examine the long-term effects of internalization on the various dimensions of performance. Similarly, this analysis could, if applied to other tourist subsectors or service organizations, extend knowledge of internalization. The study focuses on the Q certificate in Spanish hotels and therefore the results are not applicable to other external quality standards in other contexts. It would be interesting to replicate this study using data from organizations with other external quality certificates, or even in other sectors or other countries. In addition, other variables, such as the number of years with the quality standard, could be considered in future studies to examine the role of these variables in producing the effects of internalizing the quality standard on 
performance. Also, other relationships could be examined such as, for example, the relationship between employee results and customer results. That is, the positive effects on the results of the employees may cause positive effects for customers. Finally, the study uses a single respondent, the quality manager, and it would be interesting to interview more employees in the future.

\section{References}

Allur, E., Heras-Saizarbitoria, I. and Casadesús, M. (2014), “Internalization of ISO 9001: a longitudinal survey", Industrial Management \& Data Systems, Vol. 114, pp. 872885.

Álvarez-García, J., Del Río-Rama, M.C., Saraiva, M. and Ramos-Pires, A. (2016). "Dependency relationships between critical factors of quality and employee satisfaction”, Total Quality Management \& Business Excellence, Vol. 27, pp. 595612.

Alves Teixeira, A., Chiappetta Jabbour, C.J., Latan, H., Caldeira de Oliveira, J.H., de Souza Freitas W.R. and Borges Teixeira, T. (2017), "The importance of quality management for the effectiveness of environmental management: evidence from companies located in Brazil", Total Quality Management \& Business Excellence, in press.

Amin, M., Aldakhil, A.M., Wu, C., Rezaei, S. and Cobanoglu, C. (2017), "The structural relationship between TQM, employee satisfaction and hotel performance", International Journal of Contemporary Hospitality Management, Vol. 29 No. 4, pp. $1256-1278$.

Armstrong, J.S. and Overton, T.S. (1977), "Estimating non-response bias in mail surveys", Journal of Marketing Research, Vol. 14, pp. 396-402. 
Ataseven, C., Prajogo, D.I. and Nair, A. (2014), "ISO 9000 internalization and organizational commitment-implications for process improvement and operational performance", IEEE Transactions on Engineering Management, Vol. 61, pp. 5-17.

Bayo-Moriones, A., Merino-Díaz-de-Cerio, J. and Escamilla-de-León, S.A. (2011), “The impact of ISO 9000 and EFQM on the use of flexible work practices", International Journal of Production Economics, Vol. 130, pp. 33-42.

Boiral, O. and Roy, M.J. (2007), "ISO 9000: integration rationales and organizational impacts", International Journal of Operations \& Production Management, Vol. 27, pp. 226-247.

Bou-Llusar, J.C., Escrig-Tena, A.B., Roca-Puig, V. and Beltrán-Martín, I. (2009), “An empirical assessment of the EFQM Excellence Model: Evaluation as a TQM framework relative to the MBNQA Model", Journal of Operations Management, Vol. 27, pp. 1-22.

Briscoe, J.A., Fawcett, S.E. and Todd, R.H. (2005), "The implementation and impact of ISO 9000 among small manufacturing enterprises", Journal of Small Business Management, Vol. 43, pp. 309-330.

Bromiley, P. and Rau, D. (2014), “Towards a practice-based view of strategy", Strategic Management Journal, Vol. 35, pp. 1249-1256.

Cai, S. and Jun, M. (2018), “A qualitative study of the internalization of ISO 9000 standards: the linkages among firms' motivations, internalization processes, and performance", International Journal of Production Economics, Vol. 196, 248-260.

Carmines, E.G. and Zeller, R.A. (1979), Reliability and Validity Assessment, Sage University paper series on quantitative applications in the social sciences. N. 07-017. Beberly Hills, CA. 
Chin, W.W. (1998), "The partial least squares approach to structural equation modelling”, in Marcoulides, G.A. (Ed), Modern Methods for Business Research, Lawrence Erlbaum Associates, Mahwah, NJ.

Chow-Chua, C., Goh, M. and Wan, T.B. (2003), "Does ISO 9000 certification improve business performance?", International Journal of Quality \& Reliability Management, Vol. 20, pp. 936-953.

Christmann, P. and Taylor, G. (2006), "Firm self-regulation through international certificable standards: determinants of symbolic versus substantive implementation", Journal of International Business Studies, Vol. 37, pp. 863-878.

Curkovic, S. (2003), "Environmentally responsible manufacturing: the development and validation of a measurement model", European Journal of Operational Research, Vol. 146, pp. 130-155.

Curkovic, S., Melnyk, S., Calantone, R. and Handfield, R. (2000), "Validating the Malcolm Baldrige National Quality Award framework through structural equation modelling”, International Journal of Production Research, Vol. 38, pp. 765-791.

Deng, W.J., Yeh, M.L. and Sung, M.L. (2013), “A customer satisfaction index model for international tourist hotels: Integrating consumption emotions into the American Customer Satisfaction Index", International Journal of Hospitality Management, Vol. 35, pp. 133-140.

Fornell, C. and Larcker, D.F. (1981), "Evaluating structural equation models in unobservable variables and measurement error", Journal of Marketing Research, Vol. 18, pp. 39-50.

Gómez Gómez, J., Martínez Costa, M. and Martínez Lorente, A.R. (2015), “An in-depth review of the internal relationships of the EFQM model”, The TQM Journal, Vol. 27 No. 5, pp. 486-502. 
Green, S.B. (1991), "How many subjects does it take to do a regression analysis?", Multivariate Behavioral Research, Vol. 26 No. 3, pp. 499-510.

Hair, J.F. Jr., Hult, G.T., Ringle, C.M. and Sarstedt, M. (2017), “A Primer On Partial Least Squares Structural Equation Modeling (PLS-SEM)”. Second Edition. SAGE Publications.

Handfield, R.B, Melnyk, S.A., Calantone, R.J. and Curkovic, S. (2001), "Integrating environmental concerns into the design process: The gap between theory and practice”, IEEE Transactions on Engineering Management, Vol. 48, pp. 189-208.

Henseler, J., Dijkstra, T.J., Sarstedt, M., Ringle, C.M., Diamantopoulos, A., Straub, D.W., Ketchen Jr., D.J., Hair, J.F., Hult, G.T.M. and Calantone, R.J. (2014), “Common beliefs and reality about PLS: Comments on Rönkkö and Evermann (2013)”, Organizational Research Methods, Vol. 17 No. 2, pp. 182-209.

Henseler, J., Ringle, C.M. and Sarstedt, M. (2015), "A new criterion for assessing discriminant validity in variance-based structural equation modelling”, Journal of the Academy of Marketing, Vol. 43 No. 1, pp. 115-135.

Heras-Saizarbitoria, I. and Boiral, O. (2013), "ISO 9001 and ISO 14001: Towards a Research Agenda on Management System Standards”, International Journal of Management Reviews, Vol. 15 No. 1, pp. 47-65.

Heras-Saizarbitoria, I. and Boiral, O. (2015), "Symbolic adoption of ISO 9000 in small and médium-sized enterprises: the role of internal contingencies", International Small Business Journal, Vol. 33, 299-320.

Heras-Saizarbitoria, I., Marimón, F. and Casadesús, M. (2012), “An empirical study of the relationships within the categories of the EFQM model", Total Quality Management \& Business Excellence, Vol. 23 No. 5-6, pp. 1-18. 
Huarng, F., Horng, C. and Chen, C. (1999), “A study of ISO 9000 process, motivation and performance", Total Quality Management, Vol. 10 No. 7, pp. 1009-1025.

ICTE (2018), "E1 ICTE logra poner en marcha la Norma Internacional ISO para el sector hotelero", $\quad$ http://www.calidadturisticahoy.es/ESP/m/7/1277/general/Buscador/ElICTE-logra-poner-en-marcha-la-Norma-Internacional-ISO-para-el-sector-hotelero (Acces May 23, 2018).

Jang, W-Y. and Lin, C-I. (2008), “An integrated framework for ISO 9000 motivation, depth of ISO implementation and firm performance. The case of Taiwan", Journal of Manufacturing Technology Management, Vol. 19 No. 2, pp. 194-216.

Kim, D.Y., Kumar, V. and Kumar, U. (2012), "Relationship between quality management practices and innovation", Journal of Operations Management, Vol. 30, pp. 295312.

Kim, S.S., Lee, J. and Prideaux, B. (2014), “Effect of celebrity endorsement on tourists' perception of corporate image, corporate credibility and corporate loyalty", International Journal of Hospitality Management, Vol. 37, pp. 131-145.

Klassen, R. and McLaughlin, C. (1993), "TQM and environmental excellence in manufacturing”, Industrial Management \& Data Systems, Vol. 93, pp. 14-22.

Kusumah, L.H. and Fabianto, Y.S. (2018), "The differences in the financial performance of manufacturing companies in Indonesia before and after ISO 9000 implementation”, Total Quality Management \& Business Excellence, Vol. 29, pp. 941-957.

Lai, I.K.W. and Hitchcock, M. (2016), “A comparison of service quality attribute for stand-alone and resort-based luxury hotels in Macau: 3-dimensional importanceperformance analysis", Tourism Management, Vol. 55, pp. 139-159. 
Lo, C.K.Y., Yeung, A.C.L. and Cheng, T.C.E. (2011), "Meta-standards, financial performance and senior executive compensation in China: An institutional perspective”, International Journal of Production Economics, Vol. 129, pp. 119126.

Mak, B.L.M. (2011), "ISO certification in the tour operator sector", International Journal of Contemporary Hospitality Management, Vol. 23, pp. 115-130.

Martínez-Costa, M., Martínez-Lorente, A. and Choi, T.Y. (2008), "Simultaneous consideration of TQM and ISO 9000 on performance and motivation: an empirical study of Spanish companies”, International Journal of Production Economics, Vol. 113, pp. 23-39.

Mayr, S., Buchner, A., Erdfelder, E. and Faul, F. (2007), “A short tutorial of GPower”, Tutorials in Quantitative Methods for Psycology, Vol. 3 No. 2, pp. 51-59.

Molina-Azorín, J.F., Tarí, J.J., Pereira-Moliner, J., López-Gamero, M.D. and PertusaOrtega, E.M. (2015). "The effects of quality and environmental management on competitive advantage: a mixed methods study in the hotel industry", Tourism Management, Vol. 50, pp. 41-54.

Nair, A. and Prajogo, D. (2009), "Internalisation of ISO 9000 standards: the antecedent role of functionalist and institutionalist drivers and performance implications", International Journal of Production Research, Vol. 47 No. 16, pp. 4545-4568.

Naveh, E. and Marcus, A. (2005), "Achieving competitive advantage through implementing a replicable management standard: installing and using ISO 9000”, Journal of Operations Management, Vol. 24 No. 1, pp. 1-26.

Nunkoo, R., Teeroovengadum, V., Thomas, P. and Leonard, Ll. (2017), "Integrating service quality as a second-order factor in a customer satisfaction and loyalty model", 
International Journal of Contemporary Hospitality Management, Vol. 29 No. 12, pp. 2978-3005.

Pereira-Moliner, J., Claver-Cortés, E., Molina-Azorín, J.F. and Tarí, J.J. (2012), “Quality management, environmental management and firm performance: direct and mediating effects in the hotel industry", Journal of Cleaner Production, Vol. 37, pp. 82-92.

Pereira-Moliner, J., Pertusa-Ortega, E.M., Tarí, J.J., López-Gamero, M.D., MolinaAzorín, J.F. (2016), "Organizational design, quality management and competitive advantage in hotels", International Journal of Contemporary Hospitality Management, Vol. 28 No. 4, pp. 762-784.

Posinska, B., Dahlgaard, J.J. and Antoni, M. (2002), "The state of ISO 9000 certification: A study of Swedish organizations", The TQM Magazine, Vol. 14 No. 5, pp. 297-306.

Prajogo, D., Huo, B. and Han, A. (2012), “The effects of different aspects of ISO 9000 implementation on key supply chain management practices and operational performance", Supply Chain Management: An International Journal, Vol. 17 No. 3, pp. 306-322.

Prajogo, D.I. (2011), "The roles of firms' motives in affecting the outcomes of ISO 9000 adoption", International Journal of Operations \& Production Management, Vol. 31 No. 1, pp. $78-100$.

Ringle, C.M., Wende, S. and Becker, J.A. (2014), “SmartPLS 3”. Hamburg: SmartPLS, http://www.smartpls.de

Sánchez-Ollero, J.L., García-Pozo, A. and Marchante-Lara, M. (2015), "Measuring the effects of quality certification on labour productivity: An analysis of the hospitality sector”, International Journal of Contemporary Hospitality Management, Vol. 27 No. 6, pp. 1100-1116. 
Singh, P.J. (2008), “Empirical assessment of ISO 9000 related management practices and performance relationships", International Journal of Production Economics, Vol. 113 No. 1, pp. 40-59.

Singh, P.J., Power, D. and Chuong, S.C. (2011), "A resource dependence theory perspective of ISO 9000 in managing organizational environment", Journal of Operations Management, Vol. 29, pp. 49-64.

Su, L., Swanson, S.R. and Chen, X. (2016). "The effects of perceived service quality on repurchase intentions and subjective well-being of Chinese tourists: the mediating role of relationship quality", Tourism Management, Vol. 52, pp. 82-95.

Tarí, J.J., Heras-Saizarbitoria, I. and Pereira-Moliner, J. (2013), "Internalization of quality management in service organizations", Managing Service Quality, Vol. 23 No. 6, pp. 456-473.

Tarí, J.J., Molina, J.F. and Castejón, J.L. (2007), “The relationship between quality management practices and their effects on quality outcomes", European Journal of Operational Research, Vol. 183 No. 2, pp. 483-501.

UNWTO (2017). "Tourism highlights 2017 edition”, available at: http://www.eunwto.org/doi/pdf/10.18111/9789284419029 (accessed 14 September 2017).

Werts, C.E., Linn, R.L. and Jöreskog, K.G. (1974), "Interclass reliability estimates: Testing structural assumptions", Educational and Psychological Measurement, Vol. 34, pp. 25-33.

Withanachchi, N., Handa, Y., Karandagoda, K.K.W., Pathirage, P.P., Tennakoon, N.C.K. and Pullaperuma, D.S.P. (2007), “TQM emphasizing 5-S principles. A breakthrough for chronic managerial constraints at public hospitals in developing countries", International Journal of Public Sector Management, Vol. 20, pp. 168-177. 
Yeh, C.M. (2013), “Tourism involvement, work engagement and job satisfaction among frontline hotel employees", Annals of Tourism Research, Vol. 42, pp. 214-239. 
Table I. Evaluation of the measurement model

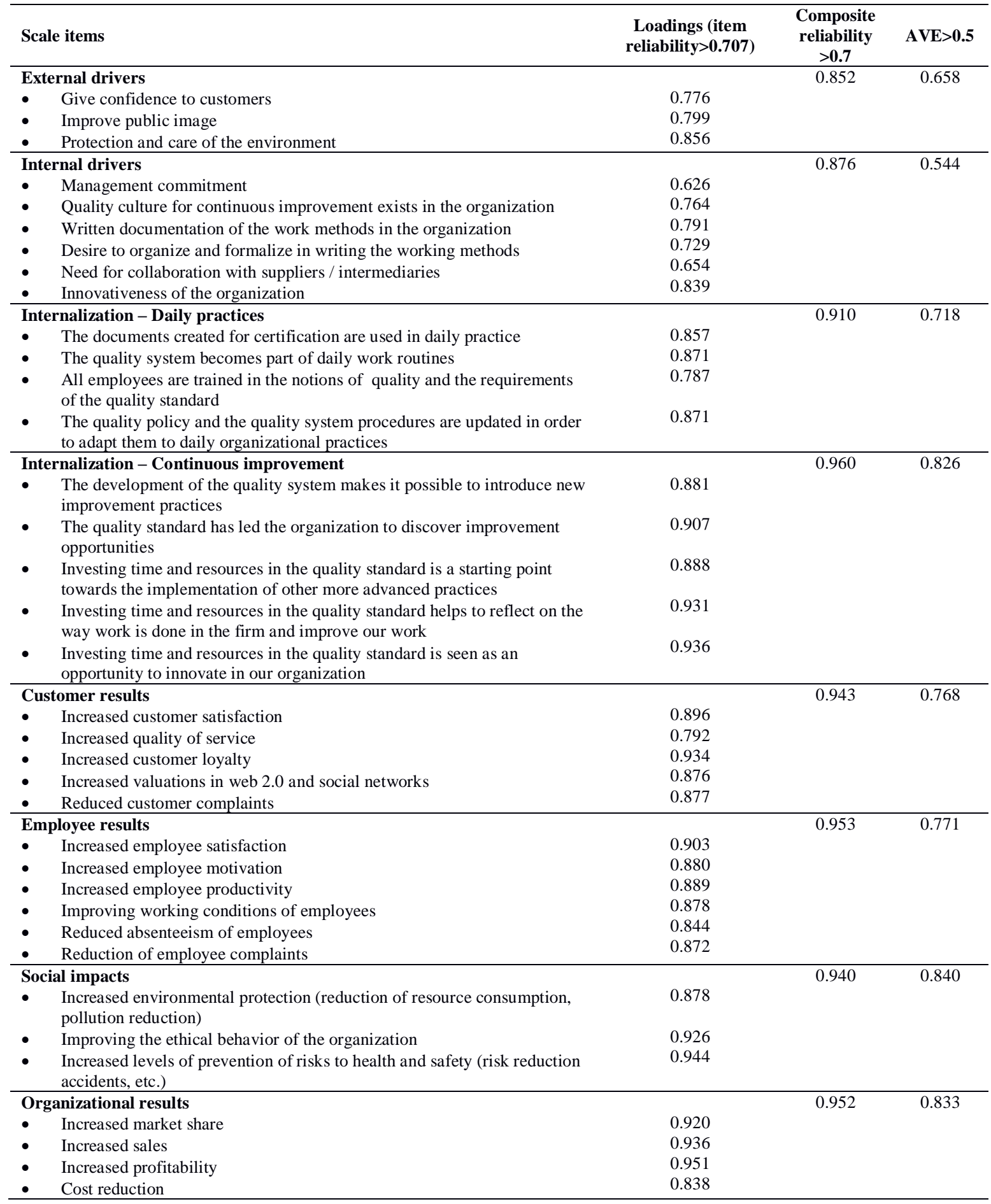


Table II. Discriminant and HTMT validity

\begin{tabular}{|c|c|c|c|c|c|c|c|c|c|c|c|c|c|c|c|}
\hline & \multicolumn{8}{|c|}{ Fornell-Larker ${ }^{(\mathrm{a})}$ discriminant validity } & \multicolumn{6}{|c|}{ HTMT validity } & \multirow[b]{2}{*}{7} \\
\hline & 1 & 2 & 3 & 4 & 5 & 6 & 7 & 8 & 1 & 2 & 3 & 4 & 5 & 6 & \\
\hline 1. External drivers & $(0.811)$ & --- & --- & --- & --- & --- & --- & $-\cdots$ & --- & --- & --- & --- & --- & --- & --- \\
\hline 2. Internal drivers & 0.578 & $(0.738)$ & --- & --- & --- & --- & --- & --- & 0.688 & --- & --- & --- & --- & --- & --- \\
\hline 3. Daily practices & 0.294 & 0.440 & $(0.847)$ & --- & --- & --- & --- & --- & 0.359 & 0.510 & --- & --- & --- & --- & --- \\
\hline $\begin{array}{l}\text { 4. Continuous } \\
\text { improvement }\end{array}$ & 0.292 & 0.455 & 0.673 & $(0.909)$ & --- & --- & --- & --- & 0.328 & 0.513 & 0.734 & --- & --- & --- & --- \\
\hline 5. Customer results & 0.484 & 0.500 & 0.368 & 0.526 & $(0.876)$ & --- & --- & -- & 0.573 & 0.564 & 0.397 & 0.555 & --- & --- & --- \\
\hline 6. Employee results & 0.412 & 0.581 & 0.460 & 0.649 & 0.746 & $(0.878)$ & --- & --- & 0.483 & 0.656 & 0.504 & 0.685 & 0.796 & --- & --- \\
\hline 7. Social impacts & 0.492 & 0.559 & 0.444 & 0.560 & 0.676 & 0.715 & $(0.916)$ & --- & 0.570 & 0.642 & 0.498 & 0.604 & 0.731 & 0.772 & --- \\
\hline $\begin{array}{l}\text { 8. Organizational } \\
\text { results }\end{array}$ & 0.445 & 0.439 & 0.355 & 0.572 & 0.812 & 0.715 & 0.620 & $(0.912)$ & 0.530 & 0.496 & 0.390 & 0.609 & 0.826 & 0.762 & 0.669 \\
\hline
\end{tabular}
The diagonal values (between brackets)
be greater than the off diagonal values. 
Figure 1. Structural model results (significant relationships) ${ }^{(a)}$

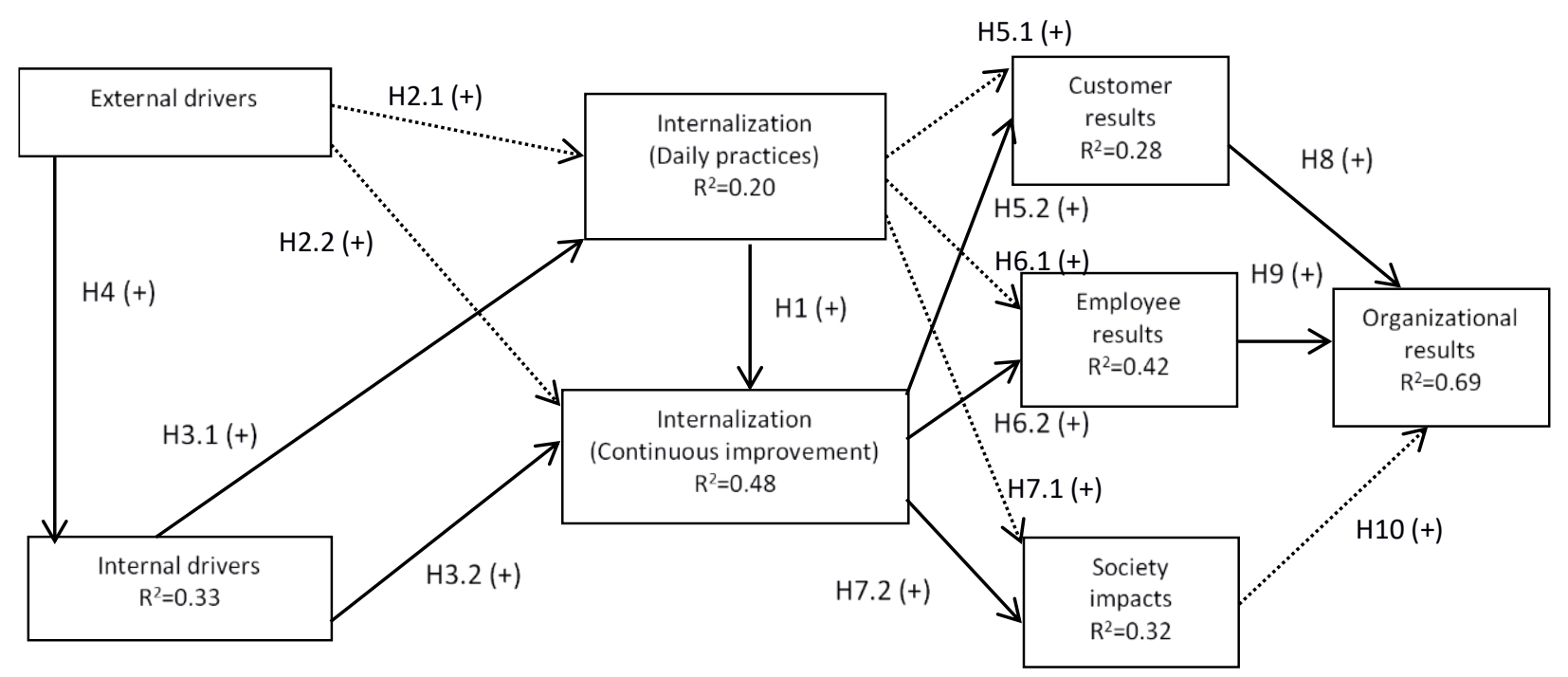

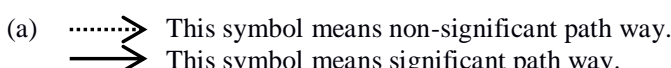

Table III Significance analysis of the structural model

\begin{tabular}{|c|c|c|c|c|c|c|}
\hline Hypotheses & $\boldsymbol{\beta}$ & t-value & p-value & $\begin{array}{c}\text { Is the } \\
\text { hypothesis } \\
\text { supported? }\end{array}$ & $\begin{array}{c}95 \% \\
\text { Confidence } \\
\text { interval } \\
\end{array}$ & $\mathbf{f}^{2}$ \\
\hline H1 Daily practices $\rightarrow$ Continuous improvement & 0.586 & 9.627 & $0.000 * * *$ & Yes & {$[0.49 ; 0.69]$} & $\begin{array}{c}\mathbf{0 . 5 3 5} \\
\text { (substantial) }\end{array}$ \\
\hline H2.1 External drivers $\rightarrow$ Daily practices & 0.059 & 0.668 & $0.252(\mathrm{NS})$ & No & {$[-0.10 ; 0.20]$} & 0.003 \\
\hline H2.2 External drivers $\rightarrow$ Continuous improvement & 0.009 & 0.112 & $0.456(\mathrm{NS})$ & No & {$[-0.13 ; 0.13]$} & 0.000 \\
\hline H3.1 Internal drivers $\rightarrow$ Daily practices & 0.406 & 4.983 & $0.000 * * *$ & Yes & {$[0.28 ; 0.55]$} & 0.137 (weak) \\
\hline H3.2 Internal drivers $\rightarrow$ Continuous improvement & 0.192 & 2.210 & $0.014 *$ & Yes & {$[0.05 ; 0.35]$} & 0.042 (weak) \\
\hline H4 External drivers $\rightarrow$ Internal drivers & 0.578 & 10.513 & $0.000 * * *$ & Yes & {$[0.49 ; 0.64]$} & $\begin{array}{c}\mathbf{0 . 5 0 2} \\
\text { (substantial) }\end{array}$ \\
\hline H5.1 Daily practices $\rightarrow$ Customer results & 0.026 & 0.291 & $0.386(\mathrm{NS})$ & No & {$[-0.11 ; 0.18]$} & 0.001 \\
\hline H5.2 Continuous improvement $\rightarrow$ Customer results & 0.509 & 5.499 & $0.000 * * *$ & Yes & {$[0.36 ; 0.65]$} & $\begin{array}{c}0.196 \\
\text { (moderate) }\end{array}$ \\
\hline H6.1 Daily practices $\rightarrow$ Employee results & 0.043 & 0.521 & $0.301(\mathrm{NS})$ & No & {$[-0.09 ; 0.18]$} & 0.002 \\
\hline H6.2 Continuous improvement $\rightarrow$ Employee results & 0.620 & 8.162 & $0.000 * * *$ & Yes & {$[0.49 ; 0.74]$} & $\begin{array}{c}\mathbf{0 . 3 6 4} \\
\text { (substantial) }\end{array}$ \\
\hline H7.1 Daily practices $\rightarrow$ Social impacts & 0.123 & 1.220 & $0.112(\mathrm{NS})$ & No & {$[-0.03 ; 0.30]$} & 0.012 \\
\hline H7.2 Continuous improvement $\rightarrow$ Social impacts & 0.477 & 4.509 & $0.000 * * *$ & Yes & {$[0.29 ; 0.64]$} & $\begin{array}{c}0.184 \\
\text { (moderate) }\end{array}$ \\
\hline H8 Customer results $\rightarrow$ Organizational results & 0.613 & 9.436 & $0.000 * * *$ & Yes & {$[0.50 ; 0.72]$} & $\begin{array}{c}0.483 \\
\text { (substantial) }\end{array}$ \\
\hline H9 Employee results $\rightarrow$ Organizational results & 0.228 & 3.629 & $0.000 * * *$ & Yes & {$[0.11 ; 0.32]$} & 0.060 (weak) \\
\hline H10 Social impacts $\rightarrow$ Organizational results & 0.042 & 0.502 & $0.308(\mathrm{NS})$ & No & {$[-0.10 ; 0.18]$} & 0.002 \\
\hline
\end{tabular}

